\title{
Diagnóstico por Imagem das Malformações Vasculares
}

\author{
Souza, AJ. ${ }^{1}$ \\ ${ }^{1}$ Belo Horizonte - Brasil. \\ E-mail: adrianosouza.vasc@gamil.com
}

Souza, A.J. 2013. Diagnóstico por Imagem das Malformações Vasculares, p.46. In: Bastos, Francisco Reis. Anais do V Simpósio Internacional de Flebologia [Blucher Medical Proceedings n.1 v.1]. São Paulo: Blucher, 2014 http://dx.doi.org/10.5151/medpro-flebo-SIF_25
Os tumores e as malformações vasculares compreendem uma grande e heterogênea gama de lesões que representam um desafio diagnóstico e terapêutico. O uso freqüente de uma nomenclatura inadequada tem levado a uma considerável confusão. Desde que a estratégia terapêutica depende do tipo de anomalia vascular, o diagnóstico e classificação corretos são cruciais. O ultra-som Doppler é considerado o método de escolha para avaliação inicial das lesões de partes moles com presumível origem vascular, podendo avaliar o grau de vascularização destas lesões e ainda diferenciar aquelas lesões de alto fluxo das de baixo fluxo. Entretanto, apresenta limitações como pequeno campo de visão, penetração limitada e por ser extremamente operador-dependente. A Ressonância Magnética é a mais valiosa modalidade para classificação das anomalias vasculares porque demonstra com grande acurácia a extensão da lesão e sua relação com estruturas adjacentes. Associada à ressonância magnética utilizamos a angiorressonância dinâmica (time-resolved) com administração de meio de contraste paramagnético (gadolínio), que nos fornece uma compreensão da hemodinâmica dos vasos envolvidos e diferenciação das lesões de alto fluxo das de baixo fluxo. A ressonância magnética é útil também na avaliação pós-tratamento das anomalias vasculares permitindo uma estratégia a longo prazo.

Palavras chave: malformações vasculares, classificação, diagnóstico, ultrasom, ressonância magnética. 